\title{
Morphology and thickness of the diffusion of resin through demineralized or unconditioned dentinal matrix
}

\section{Morfologia e espessura da difusão de resina através da matriz de dentina desmineralizada ou sem condicionamento}

\author{
César Augusto Galvão Arrais* \\ Marcelo Giannini**
}

\begin{abstract}
The formation of a hybrid layer is the main bonding mechanism of current dentin-bonding systems. This study evaluated the morphology and thickness of the resin-infiltrated dentinal layer after the application of adhesive systems. The dentin-bonding agents were evaluated on flat dentinal preparations confected on the occlusal surfaces of human teeth. The test specimens were prepared and inspected under scanning electron microscopy at a magnification of X 2,000. The adhesive systems were responsible for different hybrid layer thicknesses $(\mathrm{p}<0.05)$, and the mean values were: for Scotchbond MP Plus (SM), $7.41 \pm 1.24 \mu \mathrm{m}$; for Single Bond (SB), $5.55 \pm 0.82 \mu \mathrm{m}$; for Etch \& Prime 3.0 (EP), $3.86 \pm 1.17 \mu \mathrm{m}$; and for Clearfil SE Bond (CB), $1.22 \pm 0.45 \mu \mathrm{m}$. The results suggest that the conventional three-step adhesive system (SM) was responsible for the thickest hybrid layer, followed by the one-bottle adhesive (SB). The self-etching adhesives, EP and CB, produced the formation of the thinnest hybrid layers.
\end{abstract}

UNITERMS: Dentin; Dentin-bonding agents.

\begin{abstract}
RESUMO: A formação da camada híbrida representa o principal mecanismo de união dos sistemas adesivos odontológicos. Este estudo avaliou a micromorfologia e a espessura da camada híbrida formada por adesivos dentinários. Os adesivos foram avaliados em preparos planificados de dentina na região oclusal de dentes humanos. Os espécimes foram preparados e analisados em MEV sob $2.000 \mathrm{X}$ de magnitude. Os sistemas adesivos mostraram formação de diferentes espessuras de camada híbrida $(\mathrm{p}<0,05)$ e suas médias foram $(\mu \mathrm{m})$ : para o Scotchbond MP Plus (SM), 7,41 \pm 1,24; para o Single Bond (SB), 5,55 \pm 0,82; para o Etch \& Prime 3.0 (EP), 3,86 $\pm 1,17$ e, para o Clearfil SE Bond (CB), 1,22 $\pm 0,45$. Os resultados sugerem que o adesivo convencional (SM) seguido do adesivo de frasco único (SB) mostraram a formação das camadas híbridas com maior espessura, enquanto os adesivos autocondicionantes EP e $\mathrm{CB}$, formaram respectivamente as mais delgadas.
\end{abstract}

UNITERMOS: Dentina; Adesivos dentinários.

\section{INTRODUCTION}

Adhesive restorative techniques have become more acceptable as to their their clinical performance due to the improvement of the bonding of resin to enamel and dentin ${ }^{5}$. Several authors have reported that to obtain proper bonding it is essential to form a hybrid layer in the composite resin-dentin interface ${ }^{7,5,13,19}$. The formation of the hybrid layer was firstly described by Nakabayashi et al. ${ }^{9}$ (1982). It results in a micromechanically interlocked entanglement that originates a mixed structure composed of a demineralized collagen network surrounded by resin monomers.

The conventional adhesive systems are utilized in three steps, which include etching of dentin and enamel with phosphoric acid, application of hydrophilic primers and application of an adhesive re- sin. Acid etching removes the smear layer, opens dentinal tubules, increases dentinal permeability and demineralizes peritubular and intertubular dentin. After rinsing with water, approximately $70 \%$ of the volume of demineralized dentin, or $50 \%$ of the intertubular area, is filled by water, which replaces the removed minerals ${ }^{3,11,13}$.

Most primers are composed of one or more resin monomers, which contain two functional groups (hydrophilic and hydrophobic groups) dissolved in acetone, water, ethanol, or some combination of these solvents. The infiltration of the adhesive into the wet demineralized dentin is possible due to the hydrophilic character of the primer. The dentin-bonding agent must physically replace water in order to infiltrate the spaces between the exposed collagen fibrils. Organic solvents have the ability to

\footnotetext{
*Graduate Student (Master Degree).

**Assistant Professor, Department of Restorative Dentistry, Piracicaba School of Dentistry, University of Campinas, Brazil.
} 
Arrais CAG, Giannini M. Morphology and thickness of the diffusion of resin through demineralized or unconditioned dentinal matrix. Pesqui odontol Bras 2002;16(2):115-120.

carry resin monomers, thereby facilitating infiltration of the adhesive into the wet dentinal substrate. The hydrophobic group has an affinity for the adhesive resin, which finalizes the application of conventional adhesive systems ${ }^{5}$.

In order to simplify the bonding procedure by reducing the number of bottles and steps, manufacturers have attempted to combine either etchant and primer or primer and bonding resin. One-bottle adhesive systems combine the functions of the primer and adhesive components of conventional three-step adhesives. However, these systems still require a separate conditioning step $^{7,13,19}$.

Self-etching primers are generally less technique-sensitive, when compared with systems that require a separate acid-etching step and the "wet-bonding" protocol ${ }^{11}$. Regarding the bonding mechanism, the acidic primer allows for the incorporation of the smear layer into the hybrid layer. Moreover, the acidic resin monomer must still be able to penetrate beyond the smear layer into the underlying mineralized dentin after its early reaction with mineral components of the smear layer ${ }^{18}$.

The formation, quality and morphology of the resin-dentin interdiffusion zone have been an important topic of the researches on adhesives systems $\mathrm{s}^{6,13,14,16,18,19}$. This study investigated the micromorphology and thickness of the hybrid layer formed at the interface between the composite resin and the dentinal surface.

\section{MATERIAL AND METHODS}

The teeth utilized in this study were obtained accordingly to the protocol $(25 / 2001)$ analyzed and approved by the Ethical Committee in Research, Piracicaba Dentistry School, UNICAMP, and with the informed consent of donors. Sixteen sound human third molars, refrigerated in a solution of $2 \%$ formalin for up to two weeks after extraction, were utilized in this study. The teeth were cleaned of gross debris and stored in distilled water for twenty-four hours before the beginning of the experiment.

Roots were removed using a diamond disk (KG Sorensen) mounted in a low-speed handpiece. The crowns were mesiodistally sectioned with a diamond saw (650 - SBT), under water lubrication, in order to obtain thirty-two half-crowns. The thickness of the dentinal substrate has been considered an important experimental variable ${ }^{15,23}$. Therefore, the occlusal enamel perpendicular to the long axis of the crown was removed, and $2.0 \mathrm{~mm}$ of dentin were left from the flat dentinal surface to the roof of the pulp chamber of each specimen - the thickness of the remaining dentin was measured by means of a digital micrometer (Starrett).

Flat dentinal surfaces were wet-abraded with 600-grit silicon carbide paper (3M), for twenty seconds, in order to create a standardized smear la$\operatorname{yer}^{10,16,17,20,21}$. The test specimens were randomly divided into four groups $(\mathrm{n}=8)$, which underwent the application of a conventional three-step adhesive system (Scotchbond MP Plus), a one-bottle system (Single Bond) and two self-etching systems (Etch \& Prime 3.0 and Clearfil SE Bond). After each adhesive system was utilized according to the manufacturers' instructions, the composite resin Z100 (3M) was applied and cured for forty seconds. The bonded test specimens were then stored in distilled water for twenty-four hours at $37^{\circ} \mathrm{C}$. The composition and $\mathrm{pH}$ values of the dentin-bonding agents are shown in Table 1.

The axial surfaces of the test specimens, created by means of mesiodistal sectioning, were polished using wet aluminum oxide paper $(600,1000$ and 1200 grit) and diamond pastes (6, 3, 1 and $1 / 4 \mu \mathrm{m})$ on a polishing machine (APL-4 - Arotec). Each specimen was etched with $37 \%$ phosphoric acid for five seconds to facilitate the observation of the hybrid layer on the resin-dentin interface.

For scanning electron microscopy (SEM), the specimens were fixed in Karnovsky solution, postfixed in osmium tetroxide solution, dehydrated in ascending acetone concentration $(30,50,70,90$ and 100\%), critical-point dried (CPD 030 - Balzers) and sputter-coated with gold (MED 010 - Balzers). Each specimen was examined at a magnification of X 2,000 magnification (DSM 940A - Zeiss) so that the thickness of the hybrid layer could be measured. The measurements and the micromorphological study were carried out on the area above the pulp chamber. A tool of the scanning electron microcope allowed to measure the thickness of the hybrid layer and the results are expressed in $\mu \mathrm{m}$. The mean values of thickness of the hybrid layer were statistically analyzed by means of the oneway analysis of variance (ANOVA) and Tukey's test, at a level of significance of $5 \%$.

\section{RESULTS}

The one-way ANOVA (Table 2) revealed a statistically significant difference between the groups $(p<0.05)$. The data were further analyzed by 
Arrais CAG, Giannini M. Morphology and thickness of the diffusion of resin through demineralized or unconditioned dentinal matrix. Pesqui odontol Bras 2002;16(2):115-120.

TABLE 1 - Composition of the adhesive systems utilized in this study.

\begin{tabular}{l|l}
\hline \hline \multicolumn{1}{c|}{ Adhesive systems } & \multicolumn{1}{c}{ Composition } \\
\hline $\begin{array}{l}\text { Scotchbond MP Plus (conventional } \\
\text { three-step - 3M Dental Products) }\end{array}$ & $\begin{array}{l}\text { Conditioner }{ }^{12}: 35 \% \text { phosphoric acid (pH 0.02). } \\
\text { Primer }^{15}: \text { HEMA, PAA and water (pH 3.5). } \\
\text { Adhesive: Bis-GMA and HEMA. }\end{array}$ \\
\hline $\begin{array}{l}\text { Single Bond (one-bottle - 3M Den- } \\
\text { tal Products) }\end{array}$ & $\begin{array}{l}\text { Conditioner }{ }^{12}: 35 \% \text { phosphoric acid (pH 0.02). } \\
\left.\text { Adhesive: Bis-GMA, HEMA, PAA, ethanol and water (pH } 5^{*}\right) .\end{array}$ \\
\hline $\begin{array}{l}\text { Etch \& Prime 3.0 (self-etching - } \\
\text { Degussa Hüls) }\end{array}$ & $\begin{array}{l}\text { Universal: HEMA, ethanol and water. } \\
\left.\text { Catalyst }{ }^{2}: \text { Tetra-methacryloxyethilpyrophosphate and HEMA (pH of mixture }=1,4\right) .\end{array}$ \\
\hline $\begin{array}{l}\text { Clearfil SE Bond (self-etching - } \\
\text { Kuraray Co.) }\end{array}$ & $\begin{array}{l}\text { SE-Primer }{ }^{19}: \text { MDP, HEMA, CQ, N,N-Diethanol p-toluidine, hydrophilic dimethacrylate } \\
\text { and water (pH 2). } \\
\text { SE-Bond: MDP, Bis-GMA, HEMA, hydrophobic dimethacrylate, CQ, N,N-Diethanol } \\
\text { p-toluidine e silanated colloidal silica. }\end{array}$ \\
\hline \hline
\end{tabular}

${ }^{*} \mathrm{pH}$ as reported by the manufacturer. HEMA = 2-hydroxyethyl methacrylate; PAA = polyalkenoic acid copolymer; Bis-GMA = bisphenol-glycidyl methacrylate; $\mathrm{MDP}=10$-methacryloxydecil-dihydrogen phosphate; CQ = dil-camphorquinone.

TABLE 2 - One-way analysis of variance.

\begin{tabular}{l|r|r|r|l}
\hline \hline \multicolumn{1}{c|}{ Source } & $\begin{array}{r}\text { Sum of } \\
\text { squares }\end{array}$ & df & $\begin{array}{c}\text { Mean } \\
\text { square }\end{array}$ & F-value \\
\hline Adhesive system & 165.74 & 3 & 55.25 & $58.78^{*}$ \\
\hline Residual & 26.40 & 28 & 0.94 & \\
\hline Total & 192.14 & 31 & & \\
\hline \hline
\end{tabular}

*Statistically significant at the level of $5 \%$.

means of the Tukey's test, which revealed that adhesives formed hybrid layers with different thicknesses $(p<0.05)$. Table 3 displays the mean values of thickness of the hybrid layer and standard deviations for each adhesive system. The conventional three-step adhesive Scotchbond MP Plus formed the thickest hybrid layer $(7.41 \pm 1.24 \mu \mathrm{m})$, while the self-etching system Clearfil SE Bond formed the thinnest hybrid layer $(1.22 \pm 0.45 \mu \mathrm{m})$. When the bonding systems were applied on dentin conditioned with phosphoric acid, the thickness of the resin-infiltrated layers was greater than that observed after the utilization of self-etching dentin-bonding systems, which were applied directly to the smear layer.

The penetration of resin monomers into dentinal tubules and the formation of a resin-dentin interdiffusion zone, or hybrid layer, were observed in all groups. Figures 1, 2, 3 and 4 show the interfaces formed by the adhesives systems. The resin penetrated into dentinal tubules up to $40 \mu \mathrm{m}$, for-
TABLE 3 - Mean values of thickness $(\mu \mathrm{m})$ of the resin-dentin interdiffusion zone.

\begin{tabular}{l|c|c|c}
\hline \hline \multicolumn{1}{c|}{ Adhesive system } & Mean $\pm \mathrm{sd}$ & Range & $\begin{array}{c}\text { Tukey } \\
(5 \%)\end{array}$ \\
\hline Scotchbond MP Plus & $7.41 \pm 1.24 \mathrm{a}$ & $4.76-8.82$ & \\
\hline Single Bond & $5.55 \pm 0.82 \mathrm{~b}$ & $4.23-6.52$ & 1.32 \\
\hline Etch \& Prime 3.0 & $3.86 \pm 1.17 \mathrm{c}$ & $3.00-6.17$ & \\
\hline Clearfil SE Bond & $1.22 \pm 0.45 \mathrm{~d}$ & $0.70-2.10$ & \\
\hline \hline
\end{tabular}

$\mathrm{sd}=$ standard deviation. Mean values followed by different letters were significantly different from each other.

ming a funnel-shaped configuration of the tag neck. Some lateral branches of adhesive were observed for all dentin-bonding agents - they are the result of the penetration of monomer into lateral canals, which communicate with adjacent tubules.

\section{DISCUSSION}

Although self-etching primers present less acidity than $35 \%$ phosphoric acid gels ${ }^{12}$, they have been able to etch through the smear layer into the underlying mineralized dentin and form a hybridized complex. For self-etching adhesives, the hybridized complex comprises two portions: the zone of authentic hybrid layer and the zone of hybridized smear layer. The authentic hybrid layer is that portion where collagen fibrils remain attached to 
Arrais CAG, Giannini M. Morphology and thickness of the diffusion of resin through demineralized or unconditioned dentinal matrix. Pesqui odontol Bras 2002;16(2):115-120.

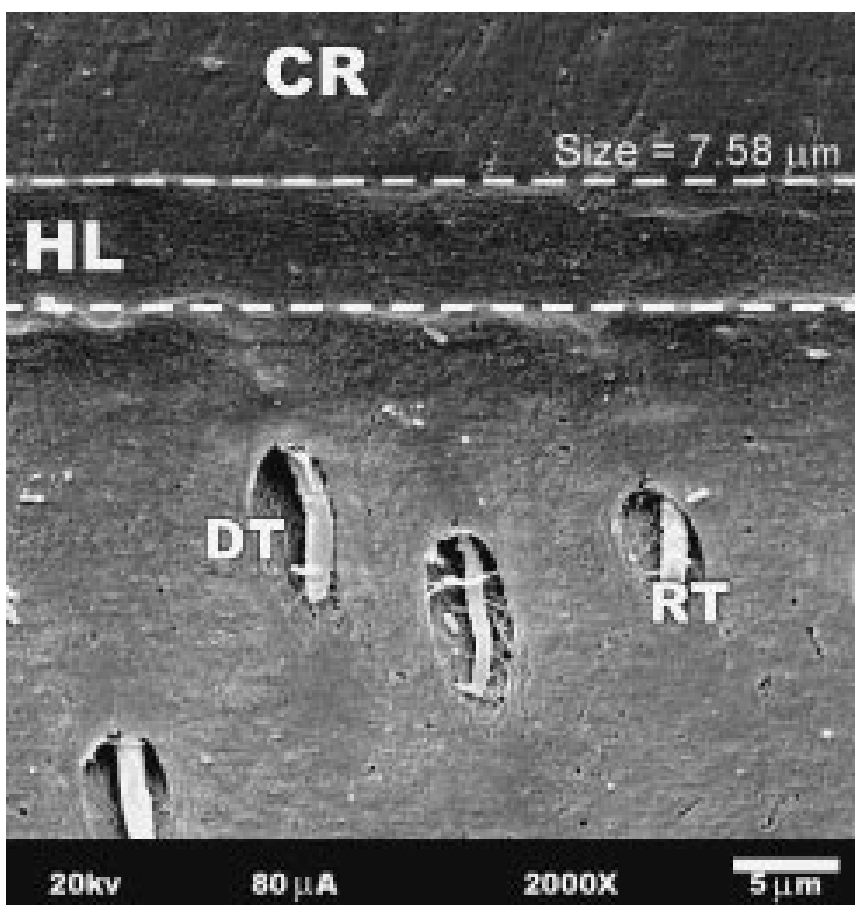

FIGURE 1 - Photomicrograph of the resin-dentin interface formed by Scotchbond MP Plus. $\mathrm{CR}=$ composite resin, $\mathrm{HL}=$ hybrid layer, $\mathrm{RT}=$ resin tag, DT = dentinal tubule.



FIGURE 2 - Photomicrograph of the resin-dentin interface formed by Single Bond. CR = composite resin, $\mathrm{HL}=$ hybrid layer, $\mathrm{RT}=$ resin tag, $\mathrm{DT}=$ dentinal tubule .

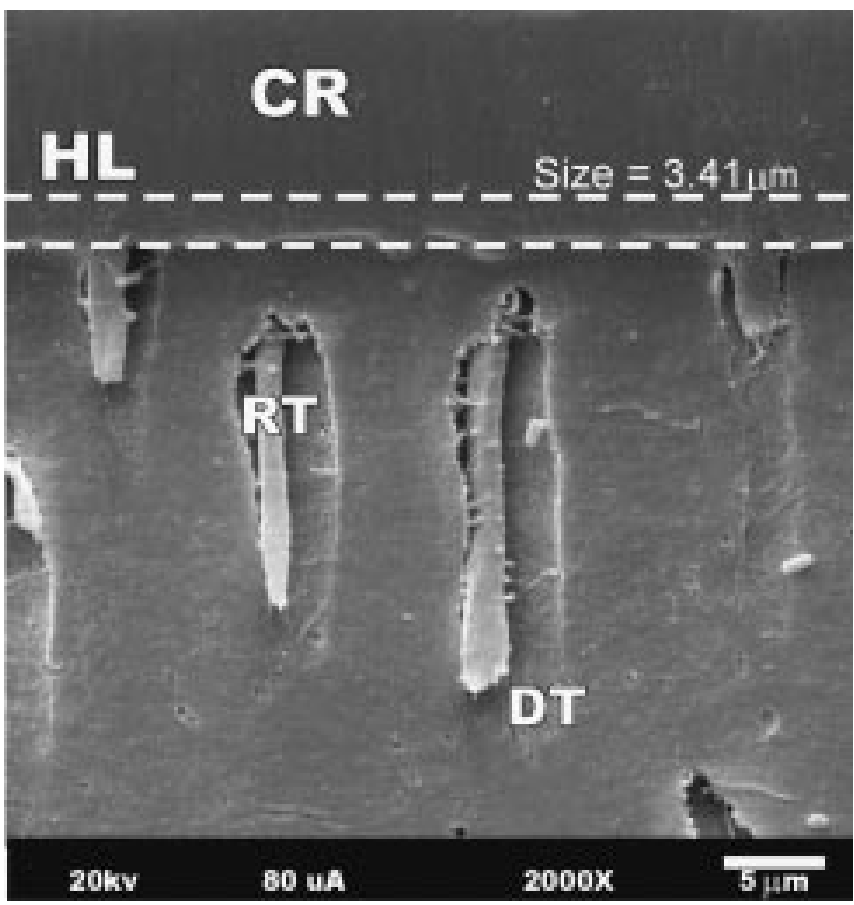

FIGURE 3 - Photomicrograph of the resin-dentin interface formed by Etch \& Prime 3.0. CR = composite resin, $\mathrm{HL}=$ hybrid layer, $\mathrm{RT}=$ resin tag, $\mathrm{DT}=$ dentinal tubule.



FIGURE 4 - Photomicrograph of the resin-dentin interface formed by Clearfil SE Bond. CR = composite resin, $\mathrm{HL}=$ hybrid layer, $\mathrm{RT}=$ resin tag, $\mathrm{DT}=$ dentinal tubule. 
Arrais CAG, Giannini M. Morphology and thickness of the diffusion of resin through demineralized or unconditioned dentinal matrix. Pesqui odontol Bras 2002;16(2):115-120.

the underlying dentin, and the hybridized smear layer is the portion above it, where the smear layer is incorporated into a hybridized complex ${ }^{18}$.

The early versions of self-etching adhesives ${ }^{4,20}$ contained Phenyl-P, as the acidic monomer, and HEMA, which resulted in a solution with a $\mathrm{pH}$ value of 1.4-0.84. Clearfil Liner Bond II etched beyond the smear layer and demineralized the underlying dentin to a depth of $1.2-1.4 \mu \mathrm{m}^{18}$. Studies have reported that these self-etching adhesives formed a 1-2- $\mu$ m-thick hybrid layer ${ }^{6,8,14,18,21}$, which is rarely thicker than $2.5 \mu \mathrm{m}^{10,24}$.

Clearfil SE Bond replaced Phenyl-P by another acidic phosphate resin monomer (MDP) and its primer showed $\mathrm{pH}=2.0$. Tay et al. ${ }^{18}(2000)$ analyzed the effect of the acidity of self-etching primers and the thickness of the smear layer. They reported an underlying authentic hybrid layer with the thickness of 0.4 to $0.5 \mu \mathrm{m}$ and a hybridized smear layer with the thickness of 0.4 to $0.7 \mu \mathrm{m}$ for Clearfil SE Bond. The aforementioned authors prepared the specimens for transmission electron microscopy and, regardless of the different methods of preparation $^{16}$, the range of thickness of the hybridized complex (0.8-1.2 $\mu \mathrm{m})$ observed in their study includes the mean value obtained in our experiment.

Studies reported that the depth of demineralized dentin is related to the concentration and $\mathrm{pH}$ of the acidic monomer ${ }^{2,4,20}$. Thus, a minimum $\mathrm{pH}$ value of 2.8 is required so that the primer solution can effectively demineralize the dentin within thirty seconds ${ }^{18}$. Acidic pyrophosphate resin monomer, present in the catalyst bottle, ionizes when in contact with the water from the catalyst bottle, originating a solution ${ }^{2}$ with $\mathrm{pH}=1.4$. The acidity of the Etch \& Prime 3.0 adhesive is higher than that of the other self-etching primer, therefore, the depth of demineralized intact dentin and the thickness of the authentic hybrid layer were also greater. Although Etch \& Prime 3.0 produced the thickest hybrid layer, when compared to the other tested self-etching adhesive, studies have shown that it is less effective, on dentinal substrate, as to marginal microleakage and shear bond strength $^{1,17}$.

Similarly to what was observed for Clearfil SE Bond, the demineralization of dentin and the penetration of HEMA occur simultaneously for Etch \& Prime 3.0. The formation of a hybrid layer after the application of the Scotchbond MP Plus and Single
Bond adhesive systems depends on previous acid-ethching and on the uniform infiltration of resin monomers into the spaces between the collagen fibrils of the demineralized dentinal subsurfa$\mathrm{ce}^{9}$. The etching agent (32-37\% phosphoric acid) demineralizes dentin by removing hydroxyapatite and exposing collagen fibrils in the few microns (3-5 $\mu \mathrm{m})$ of the most superficial layer of dentin ${ }^{3,12}$. Therefore, the depth of demineralized dentin produced by phosphoric acid is greater than that produced by self-etching primers, which results in a thicker hybrid layer.

The Scotchbond MP Plus bonding system was able to produce the thickest hybrid layer (7.41 \pm $1.24 \mu \mathrm{m})$. Since the etching time and the etching agent were the same, other mechanisms must be responsible for the thicker resin-infiltrated dentinal layer seen after the application of Scotchbond MP Plus, when compared to Single Bond. A possible explanation is that this primer is more acidic (pH 3.5) than the Single Bond one-bottle adhesive (pH 5). The acidity of the primer of Scotchbond MP may have contributed to a second demineralization of the underlying dentin and, thus, allowed for deeper penetration of monomer into the demineralized dentinal matrix. Similar values of thickness of the hybrid layer have been reported for Scotchbond MP Plus s,8,14,15,19,22 and Single Bond $^{7,13,15,19}$. That confirms the validity of preparing specimens for SEM and measuring the thickness of the hybrid layer by means of the techniques employed in the present study.

\section{CONCLUSION}

According to the methodology employed and based on the obtained results and on the statistical analyses, it can be concluded that:

1. all tested adhesive systems formed a hybrid layer, although with significantly different thicknesses;

2. the conventional three-step adhesive, followed by the one-bottle adhesive, exhibited the thickest hybrid layer;

3. self-etching adhesives exhibited the thinnest hybrid layer.

\section{ACKNOWLEDGMENTS}

The authors are indebted to Professor Elliot Watanabe Kitajima (NAP-MEPA, ESALQ-USP) for the technical support in electron microscopy. 
Arrais CAG, Giannini M. Morphology and thickness of the diffusion of resin through demineralized or unconditioned dentinal matrix.

Pesqui odontol Bras 2002;16(2):115-120.

\section{REFERENCES}

1. Burmann P, Cardoso PEC, Silveira B, et al. The influence of composite resin polymerization techniques on microleakage [abstract 315]. J Dent Res 2000;79:183.

2. Cardoso PEC, Braga RR, Carrilho MRO. Evaluation of micro-tensile, shear and tensile tests determining the bond strength of three adhesive systems. Dent Mater 1998; 14:394-8.

3. Carvalho RM, Yoshiyama M, Pashley EL, et al. In vitro study on the dimensional changes of dentine after demineralization. Arch Oral Biol 1996;41:369-77.

4. Chigira H, Yukitani W, Hasegawa T, et al. Self-etching dentin primers containing phenyl-P. J Dent Res 1994; 73:1088-95.

5. Eick JD, Gwinnett AJ, Pashley DH, et al. Current concepts on adhesion to dentin. Crit Rev Oral Biol Med 1997; 8:306-35.

6. Ferrari M, Cagidiaco CM, Kugel G, et al. Dentin infiltration by three adhesive systems in clinical and laboratorial conditions. Am J Dent 1996;9:240-4.

7. Ferrari M, Goracci G, Garcia-Godoy F. Bonding mechanism of three one-bottle systems to conditioned and unconditioned enamel and dentin. Am J Dent 1997; 10:224-30.

8. Marshall SJ, Tomsia AP, Marshall GW. Resin-dentin interdiffusion zone thickness [abstract 2415]. J Dent Res 1997;76:315.

9. Nakabayashi N, Kojima K, Masuhara E. The promotion of adhesion by the infiltration of monomers into tooth substrates. J Biomed Mater Res 1982;16:265-73.

10. Nakajima M, Sano $H$, Burrow MF, et al. Tensile bond strength and SEM evaluation of caries-affected dentin using dentin adhesives. J Dent Res 1995;74:1679-88.

11. Pashley DH, Carvalho RM. Dentine permeability and dentine adhesion. J Dent 1997;25:355-72.
12. Perdigão J, Lambrechts P, Van Meerbeek B, et al. A morphological field emission SEM study of the effect of six phosphoric acid-etching agents on human dentin. Dent Mater 1996;12:262-71.

13. Perdigão J, Ramos JC, Lambrechts P. In vitro interfacial relationship between human dentin and one-bottle dental adhesives. Dent Mater 1997;13:218-27.

14. Prati C, Chersoni S, Mongiorgi R, et al. Resin infiltrated dentin layer formation of new bonding systems. Oper Dent 1998;23:185-94.

15. Prati $\mathrm{C}$, Chersoni $\mathrm{S}$, Mongiorgi $\mathrm{R}$, et al. Thickness and morphology of resin-infiltrated dentin layer in young, old and sclerotic dentin. Oper Dent 1999;24:66-72.

16. Sano H, Yoshiyama M, Ebisu S, et al. Comparative SEM and TEM observations of nanoleakage within the hybrid layer. Oper Dent 1995;20:160-67.

17. Segre INW, Giannini M, Pimenta LAF. Shear bond strength evaluation of different hydrophilic adhesive system [abstract 1850]. J Dent Res 2000;79:375.

18. Tay FR, Sano H, Carvalho RM, et al. An ultrastructural study of the influence of acidity of self-etching primers and smear layer thickness on bonding to intact dentin. J Adhes Dent 2000;2:83-98.

19. Vargas MA, Cobb DS, Denehy GE. Interfacial micromorphology and shear bond strength of single-bottle primer/adhesives. Dent Mater 1997;13:316-24.

20. Watanabe I, Nakabayashi N, Pashley DH. Bonding to ground dentin by a phenyl-P self-etching primer. J Dent Res 1994;73:1212-20.

21. Yoshiyama M, Sano H, Ebisu S, et al. Regional strengths of bonding agents to cervical sclerotic root dentin. J Dent Res 1996;75:1404-13.

22. Youssef MN, Guaraldi E, Sato CT, et al. Estudo comparativo de quatro filosofias adesivas quanto à penetração na dentina. Rev Assoc Paul Cir Dent 1998;52:236-9.

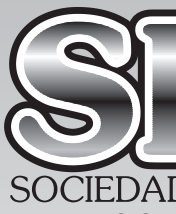

SOCIEDADE BRASILEIRA

DE PESQUISA ODONTOLÓGICA

Divisão Brasileira da IADR

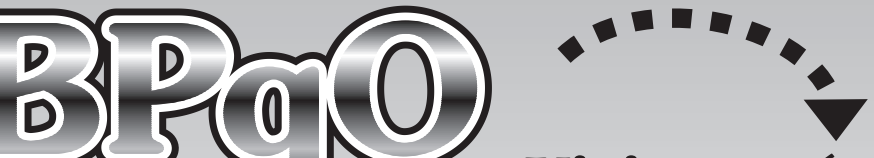

Visite a página da SBPqO na Internet: http://www.sbpqo.org.br

SBPqO - Av. Professor Lineu Prestes, 2.227

CEP 05508-900 - Cidade Universitária - São Paulo - SP Tel./Fax: (0**11) 3091-7855 - E-mail: sbpqo@sbpqo.org.br 